uninfected partners: 38.3\% (Bateyes-DR), 35.4\% (Haiti), 33.3\% (DR), 32.1\% (Cambodia), and 39.6\% (India). Limited sero-discordancy was observed at the population-level with at most two out of every 100 adults in reproductive age being engaged in a SDC.

Conclusions Our findings are consistent with HIV sero-discordancy patterns in low prevalence settings in SSA. While the large sero-discordancy among SCs affected by HIV offers an opportunity for HIV prevention, the small number of SCs affected by HIV at the population-level suggests logistical difficulties for implementing SDC-targeted prevention interventions in these countries.

\section{P3.207 THE INFLUENCE OF COLLEGE STUDENTS IN A SEXUAL NETWORK OF YOUNG AFRICAN-AMERICAN MEN}

doi:10.1136/sextrans-2013-051184.0664

'D K Pasquale, ${ }^{2} \mathrm{~A}$ Doherty, ${ }^{3} \mathrm{M}$ E Emch, ${ }^{1,2 \mathrm{~W}} \mathrm{C}$ Miller, ${ }^{4} \mathrm{E}$ M Foust, ${ }^{2,4 \mathrm{P}} \mathrm{A}$ Leone. 'University of North Carolina at Chapel Hill Gillings School of Global Public Health, Chapel Hill, NC, United States; 'University of North Carolina at Chapel Hill School of Medicine, Chapel Hill, NC, United States; ${ }^{3}$ University of North Carolina at Chapel Hill Department of Geography, Chapel Hill, NC, United States; ${ }^{4}$ North Carolina Division of Public Health, Communicable Disease Branch, Raleigh, NC, United States

Background Young Black men who have sex with men (MSM) are disproportionately affected by HIV and STIs in North Carolina (NC). Behavior and STI prevalence in the sexual network affect transmission risk; network position may be a marker for risk.

Methods We constructed the local sexual network from reportable $\mathrm{HIV}$ and syphilis cases diagnosed among Black men age 15-30 in north central NC from 2006-2009 ( $\mathrm{N}=1100)$; infected and uninfected contacts were included in the network. Bonacich power is an unbounded measure of network centrality derived from the number of contacts and number of contacts' contacts. Higher Bonacich scores represent increased centrality in the network, while accounting for the centrality of an individual's contacts. It is iterative, giving more weight to closer contacts. To assess the centrality of college status in the network, Bonacich scores and $95 \%$ confidence intervals (95\% CI) were calculated for all college-age Black men (17-24 years) $(\mathrm{n}=385)$. We computed t-tests and chi-square tests to measure score differences by college status for factors associated with HIV infection risk.

Results Bonacich scores were normally distributed (range $-57.5-$ 62.2). Mean score was higher for college than non-college men (5.86 (95\% CI: $4.69-7.04)$ v. 3.13 (95\% CI: $2.51-3.76), P<0.0001)$. College men were more likely to use dating sites and less likely to use marijuana than non-college men. Sexual orientation also differed significantly by college status: while the proportion of MSM was $\sim 70 \%$, college men were more likely to be bisexual (24\% v. $11 \%)$ and less likely to be heterosexual ( $7 \%$ v. $22 \%$ ) compared to non-college men. College status was not associated with diagnosis, STI history, alcohol use, or having anonymous partners.

Conclusion Young African-American college men are more central in this sexual network than young African-American men who are not in college, putting them at risk for HIV acquisition and transmission.

\section{P3.208 SPATIAL VARIABILITY IN THE DECLINE OF HIV PREVALENCE IN THREE COUNTRIES IN SUB-SAHARAN AFRICA}

doi:10.1136/sextrans-2013-051184.0665

D F Cuadros, S F Awad, L J Abu-Raddad. Weill Cornell Medical College in Oatar, Doha, Oatar

Background HIV prevalence is decreasing in large parts of subSaharan Africa (SSA), but the impact of this decline on the geographical heterogeneity of HIV infectious burden is not well understood. We explored and described aspects of the spatial and temporal heterogeneity of the epidemic in three countries in SSA.
Methods Data were obtained from Demographic and Health Surveys conducted at different times in Malawi, Tanzania, and Kenya. We identified and compared spatial clusters with high numbers of HIV infections at two different times from each country using Kulldorff spatial scan test. The test locates areas with higher numbers of HIV infections than expected under spatial randomness. For each identified cluster, a likelihood ratio test was computed. A $P$-value was then determined through Monte Carlo simulations to evaluate the statistical significance of each cluster.

Results The table summarises the main results. We found no evidence of decline in HIV prevalence within clusters with high HIV prevalence despite the statistically significant decline in the national HIV prevalence in Malawi and Tanzania. National HIV prevalence decreased by $19 \%$ in Malawi, and 17\% in Tanzania; meanwhile, HIV prevalence in areas outside of the clusters declined by $33 \%$ and $30 \%$, respectively. There was no statistically significant decline in the national HIV prevalence in Kenya, but HIV prevalence within clusters increased by $27 \%$.

Conclusions We found marked spatial variability in the decline of HIV prevalence in the three studied SSA countries. Even in the presence of declining national HIV prevalence, HIV prevalence in the high HIV prevalence clusters either did not decline or even increased. Most of the gains in reducing HIV disease burden did not occur in the areas of most intense HIV transmission, but in areas outside of the clusters. Our findings provide insights for resource allocation and HIV prevention interventions in these countries.

\section{Abstract P3.208 Table 1}

\begin{tabular}{|c|c|c|c|c|}
\hline Country & & $\begin{array}{l}\text { Survey } 1 \\
\text { (2003-2004) } \\
\text { HIV prevalence (\%) }\end{array}$ & $\begin{array}{l}\text { Survey } 2 \\
(2009-2010) \\
\text { HIV prevalence (\%) }\end{array}$ & $P$ value \\
\hline \multirow[t]{3}{*}{ Malawi } & National & 12.52 & 10.13 & $<0.001$ \\
\hline & Within clusters & 15.32 & 14.83 & 0.59 \\
\hline & Outside clusters & 10.35 & 6.97 & $<0.001$ \\
\hline \multirow[t]{3}{*}{ Tanzania } & National & 6.50 & 5.38 & $<0.001$ \\
\hline & Within clusters & 9.85 & 9.34 & 0.49 \\
\hline & Outside clusters & 5.13 & 3.61 & $<0.001$ \\
\hline \multirow[t]{3}{*}{ Kenya } & National & 6.59 & 6.30 & 0.62 \\
\hline & Within clusters & 10.77 & 13.72 & 0.01 \\
\hline & Outside clusters & 5.37 & 4.66 & 0.11 \\
\hline
\end{tabular}

\section{P3.209 LOW RATES OF STI CO INFECTION OBSERVED IN HIV POSITIVE WOMEN PARTICIPATING IN AN HPV VACCINE STUDY IN CANADA}

doi:10.1136/sextrans-2013-051184.0666

'E Moses, ${ }^{2} \mathrm{~S}$ Blitz, ${ }^{1} \mathrm{~J}$ Raboud, ${ }^{3} \mathrm{~J}$ Singer, ${ }^{4} \mathrm{M}$ Loutfy, ${ }^{5} \mathrm{~F}$ Smaill, ${ }^{2} \mathrm{~S}$ Walmsley, ${ }^{3} \mathrm{D}$ Money. 'University of Toronto, Toronto, ON, Canada; ${ }^{2}$ University Health Network, Toronto, ON, Canada; 'University of British Columbia, Vancouver, BC, Canada; ${ }^{4}$ Women's College Research Institute, Toronto, ON, Canada; ${ }^{5}$ McMaster University, Hamilton, ON, Canada

Background HIV positive women with sexually transmitted infections (STIs) face increased reproductive health risks and negative health outcomes. This sub-analysis was performed to determine the co-factors associated with a history of STI's in this high-risk population.

Methods Data was collected as part of an ongoing multi-centred study of the immunogenicity and safety of a quadrivalent HPV vaccine in HIV + women in Canada, Clinical data, along with genital HPV-DNA sampling and liquid based cervical cytology data, was collected 3 months prior to initial vaccination.

Results Of the 255 sexually active women in this sub-analysis, characteristics were: mean age of 37 , ethnicity: black $42 \%$, white $36 \%$, aboriginal $11 \%$ and other $10 \%$. Mean number of lifetime sexual partners 5 (3-15), 70\% of women were sexually active within 